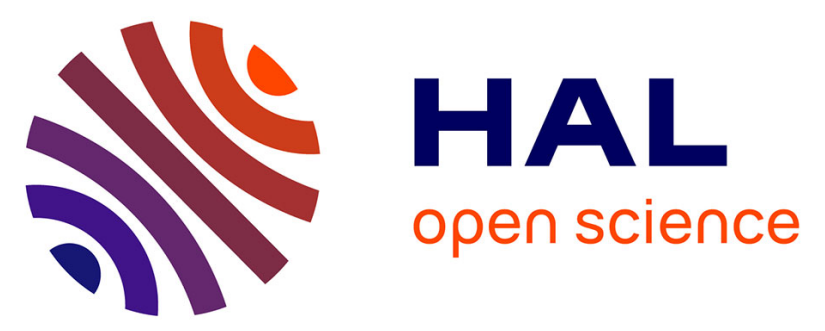

\title{
Synthesis, characterization and unusual near-infrared luminescence of 1,1,4,4-tetracyanobutadiene derivatives
} Anh Thy Bui, Clotilde Philippe, Maxime Beau, Nicolas Richy, Marie Cordier, Thierry Roisnel, Loïc Lemiègre, Olivier Mongin, Frédéric Paul, Yann Trolez

\section{- To cite this version:}

Anh Thy Bui, Clotilde Philippe, Maxime Beau, Nicolas Richy, Marie Cordier, et al.. Synthesis, characterization and unusual near-infrared luminescence of 1,1,4,4-tetracyanobutadiene derivatives. Chemical Communications, 2020, 56 (24), pp.3571-3574. 10.1039/c9cc09560h . hal-02498790

\author{
HAL Id: hal-02498790 \\ https://hal-univ-rennes1.archives-ouvertes.fr/hal-02498790
}

Submitted on 12 May 2020

HAL is a multi-disciplinary open access archive for the deposit and dissemination of scientific research documents, whether they are published or not. The documents may come from teaching and research institutions in France or abroad, or from public or private research centers.
L'archive ouverte pluridisciplinaire HAL, est destinée au dépôt et à la diffusion de documents scientifiques de niveau recherche, publiés ou non, émanant des établissements d'enseignement et de recherche français ou étrangers, des laboratoires publics ou privés. 


\title{
Synthesis, characterization and unusual near-infrared luminescence of 1,1,4,4- tetracyanobutadiene derivatives
}

\author{
Anh Thy Bui, ${ }^{a}$ Clotilde Philippe, ${ }^{a}$ Maxime Beau, ${ }^{a}$ Nicolas Richy, ${ }^{a}$ Marie Cordier, ${ }^{a}$ Thierry Roisnel, ${ }^{a}$ \\ Loïc Lemiègre, ${ }^{a}$ Olivier Mongin, ${ }^{a}$ Frédéric Paul, ${ }^{a}$ Yann Trolez $^{\mathrm{a} *}$
}

a. Univ Rennes, Ecole Nationale Supérieure de Chimie de Rennes, CNRS, ISCR-UMR6226, F-35000 Rennes, France.

Two 1,1,4,4-tetracyanobutadiene (TCBD) derivatives were prepared by $[2+2]$ cycloaddition-retroelectrocyclization from ynamides bearing either a pyrene (1) or a perylene unit (2). In addition to panchromatic absorptions in 2 , in the solid state, both compounds unexpectedly display NIR photoluminescence that could be detected up to about $1350 \mathrm{~nm}$.

1,1,4,4-tetracyanobutadiene (TCBD) compounds have attracted considerable interest in the last two decades owing to their impressive optoelectronic properties. ${ }^{1}$ In particular, they can display strong intramolecular charge-transfer (ICT) bands that are intense and/or shifted into the near-infrared (NIR) region, absorption features that span the entire visible spectrum (namely panchromatism), ${ }^{2,3}$ and high second- and third-order nonlinear optical responses. ${ }^{1 \mathrm{a}, 4}$ These peculiar species are typically synthesized by reacting an electron-rich alkyne with tetracyanoethylene (TCNE), which induces a $[2+2]$ cycloaddition followed by a retroelectrocyclization step to provide the TCBD motif. ${ }^{5}$ Although this catalyst-free reaction is recognized as a salient method to install strong electron-accepting moieties in push-pull multicomponent systems in a facile and efficient way, ${ }^{5}$ its scope of applications is limited due to the great majority of TCBD derivatives being reportedly non-emissive. In di-p-anilino-substituted TCBD, the groups of Diederich and Armaroli demonstrated that this behavior originates from the ultrafast radiationless deactivation of the $S_{1}$ state, rationalized by the existence of a twisted intramolecular charge-transfer (TICT) state minimum with a proximate conical intersection (Cl) that acts as an efficient decay funnel to the ground state. ${ }^{6}$ This provides valuable insight into the photophysics of related donor-TCBD compounds that can be expected to exhibit similar excitedstate dynamics, thereby hampering their implementation in organic photovoltaic devices. ${ }^{\mathrm{g}}$ In this context, luminescence properties of TCBD compounds are scarcely reported. In fact,

Electronic Supplementary Information (ESI) available: general and synthetic procedures, characterization data, crystallographic views and photophysical measurements. See DOI: 10.1039/x0xx00000x the observed weaker emission signals are indicative of a quenching process affecting the fluorescence of the chromophore to which the TCBD moiety is attached. ${ }^{2,7}$ Nevertheless, fluorescence arising from a charge-transfer state involving strong electronic communication with the TCBD unit has been mentioned, ${ }^{2,8 a}$ including in 2016 in an article from our laboratory that shows improved luminescence properties in solvent glasses. ${ }^{8 b}$ Furthermore, some investigations have emerged that circumvent the discussed pitfalls: the aggregation-induced emission from $J$-aggregates of a bis-TCBD compound that self-assembles into vesicles or nanotubes was described in 2008, ${ }^{9}$ and more recently Guldi, Torres, Bottari and coworkers reported a remarkable exciplex emission due to intramolecular interactions between a fluorinated subphthalocyanine and an aniline fragment spatially arranged by the distorted TCBD unit, ${ }^{10 a}$ while another report proposed urea-based TCBDs as luminophores. ${ }^{10 \mathrm{~b}}$ In the light of these studies, it appears that TCBD derivatives offer more intriguing potentialities than initially foreseen that have yet to be explored.

In 2014, we showed that ynamides ${ }^{11}$ constitute good substrates for the $[2+2]$ cycloaddition-retroelectrocyclization reaction. ${ }^{12}$ This reactivity only suffers from few exceptions, essentially due to steric hindrance or deactivation of the triple bond by employing a strong electron-withdrawing group. ${ }^{13}$ The obtained cycloadducts are inherently distinctive from anilineTCBD derivatives in that the initial electron-donating group that allows for the reaction to occur (i.e. the sulfonamide) does not ultimately induce an internal charge transfer in the TCBD, as supported by electrochemical measurements and theoretical calculations. ${ }^{12}$ Thus, the aromatic group located on the other side of the TCBD group might determine the nature of the lowest excited state. We hypothesized that this specificity could allow us to obtain emissive materials following this strategy. Herein, we would like to report on the synthesis and characterization of two new TCBD compounds constructed from ynamides and bearing pyrene (compound 1) and perylene (compound 2) groups (Fig. 1). In addition to interesting absorption properties, we found that these molecules emit light in the near-infrared region in the solid 

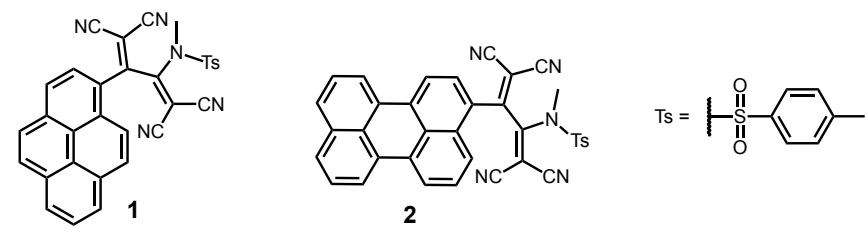

Fig. 1 Structure of the compounds $\mathbf{1}$ (bearing a pyrene) and $\mathbf{2}$ (bearing a perylene).

state, with a photoluminescence $(\mathrm{PL})$ band centered beyond $800 \mathrm{~nm}$. This unprecedented property opens new perspectives for TCBD derivatives.

We synthesized the ynamide precursors following Evano's procedure. ${ }^{14 a}$ By reacting the corresponding aldehydes 3 and $6^{14 b}$ with carbon tetrabromide and triphenylphosphine, the gem-dibromovinyl compounds $\mathbf{4}$ and $\mathbf{7}$ were isolated. They were subsequently submitted to Evano's conditions using $\mathrm{N}$ methyl- $p$-toluenesulfonamide, $N, N$-dimethylethylenediamine (DMEDA), cesium carbonate and copper iodide as catalyst to afford the corresponding ynamides $\mathbf{5}$ and $\mathbf{8}$. These precursors were then reacted with TCNE to obtain compounds $\mathbf{1}$ and $\mathbf{2}$ in $63 \%$ and $71 \%$ yield respectively (Fig. 2a), as a dark purple powder for $\mathbf{1}$ and a dark green one for $\mathbf{2}$.

These TCBD derivatives were unambiguously characterized by ${ }^{1} \mathrm{H}$ and ${ }^{13} \mathrm{C}$ NMR spectroscopy (Figs. S1-S12) as well as highresolution mass spectrometry. In addition, both of them afforded crystals suitable for X-ray diffraction by slow diffusion of cyclohexane into a dichloromethane solution. As usually encountered with TCBD moieties, the two dicyanovinyl groups are in a $s$-cis geometry since the torsion angle between them is equal to $54^{\circ}$ and $58^{\circ}$ for 1 and 2 respectively (Fig. 2b). The dicyanovinyl group adjacent to the polyaromatic structure does not stand in the same plane for steric reasons. Actually, the torsion angle between pyrene or perylene and this dicyanovinyl group is equal to $52^{\circ}$ and $44^{\circ}$, respectively. Noteworthy is the intramolecular $\pi$-stacking in compound 1 between the pyrene and the tosyl group. The distance between the two planes is about $3.5 \AA$. The situation is different from compound $\mathbf{2}$ where no intramolecular $\pi$ stacking is observed. However, intermolecular $\pi$-stacking is observed between polyaromatic units in the packing of both systems with distances between the aromatic planes of $3.5 \AA$ and $3.4 \AA$, respectively (Fig. S13 and S14). Considering the low quantity of materials obtained from growing single crystals,

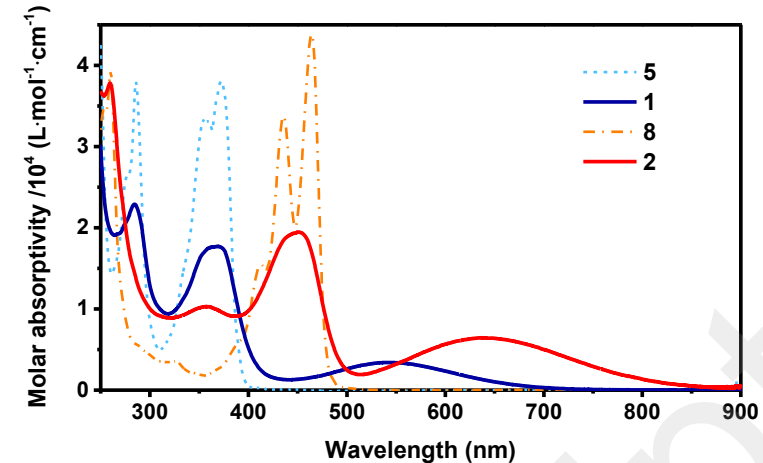

Fig. 3 UV-visible absorption spectra of compounds $\mathbf{1}$ (dark blue solid line) and $\mathbf{2}$ (red solid line), and ynamides precursors $\mathbf{5}$ (dashed blue line) and $\mathbf{8}$ (dash-dotted orange line) in dichloromethane.

powdered samples collected directly after vacuum drying of the as-synthesized compounds in solution were also analyzed by powder X-ray diffraction. The diffraction peak profiles and intensities matched the theoretical patterns calculated from the structural models derived from the single-crystal measurements, indicating that these powders are representative of the single-crystal structures (Fig. S15).

The UV-visible absorption spectra of compounds $\mathbf{1}$ and $\mathbf{2}$ were recorded in dichloromethane and present notable features extending throughout the visible range (Fig. 3). For comparison, the electronic spectra of ynamide precursors 5 and $\mathbf{8}$ were also measured. The low-energy absorption of $\mathbf{5}$ and 8 shows intense and structured bands typical of substituted pyrene and perylene derivatives, maximizing at $372 \mathrm{~nm}(\varepsilon=3.8$ $\left.\times 10^{4} \mathrm{M}^{-1} \cdot \mathrm{cm}^{-1}\right)$ and $464 \mathrm{~nm} \quad\left(\varepsilon=4.4 \times 10^{4} \mathrm{M}^{-1} \cdot \mathrm{cm}^{-1}\right)$ respectively. Though the spectra of $\mathbf{1}$ and $\mathbf{2}$ display an absorption band at comparable wavelengths, the formation of the TCBD adducts resulted in a decrease in its oscillator strength as well as a loss of the vibronic progression. More remarkably, a new absorption band becomes apparent in both compounds $\mathbf{1}$ and $\mathbf{2}$ at longer wavelengths. Pyrene derivative $\mathbf{1}$ exhibits a large absorption band between $c a 400$ and $700 \mathrm{~nm}$ with a maximum at $545 \mathrm{~nm}\left(\varepsilon=3.4 \times 10^{3} \mathrm{M}^{-1} \cdot \mathrm{cm}^{-1}\right)$. Even more remarkable is the lowest energy absorption band in compound 2 that covers a region starting from $c a 500 \mathrm{~nm}$ and going beyond $800 \mathrm{~nm}$, reaching thus the NIR region, with a maximum at $639 \mathrm{~nm}\left(\varepsilon=6.4 \times 10^{3} \mathrm{M}^{-1} \cdot \mathrm{cm}^{-1}\right)$. These extremely (a)
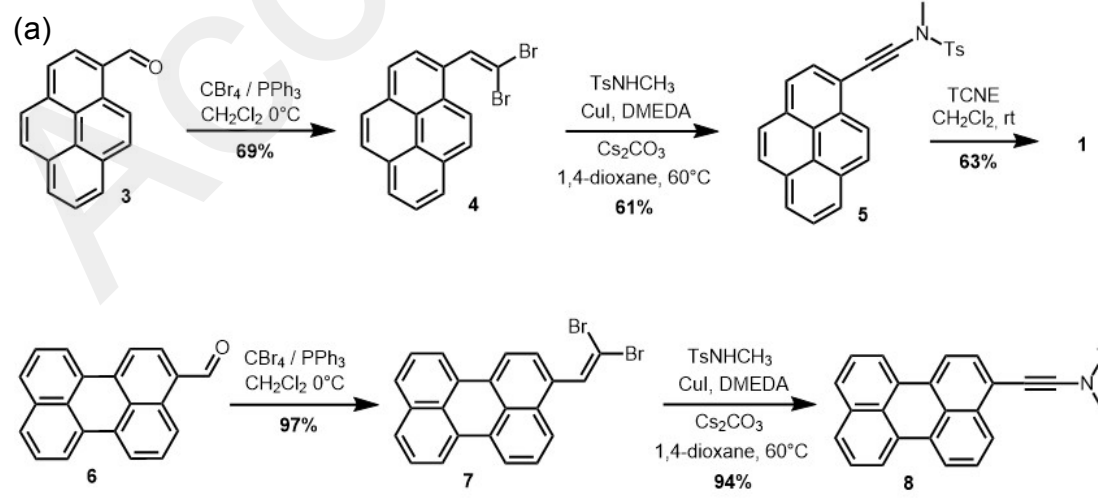

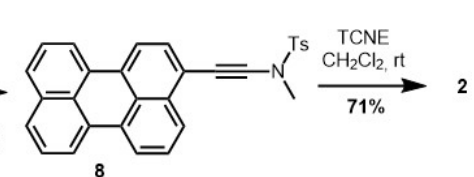

(b)
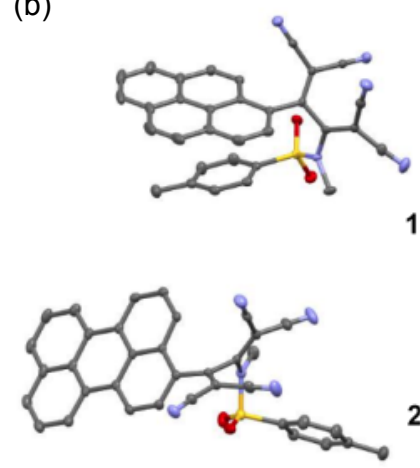

Fig. 2 (a) Synthetic route to compounds 1 and $\mathbf{2}$ and (b) their X-ray structures. Hydrogens atoms are omitted for clarity; ellipsoids are drawn with $50 \%$ probability. 


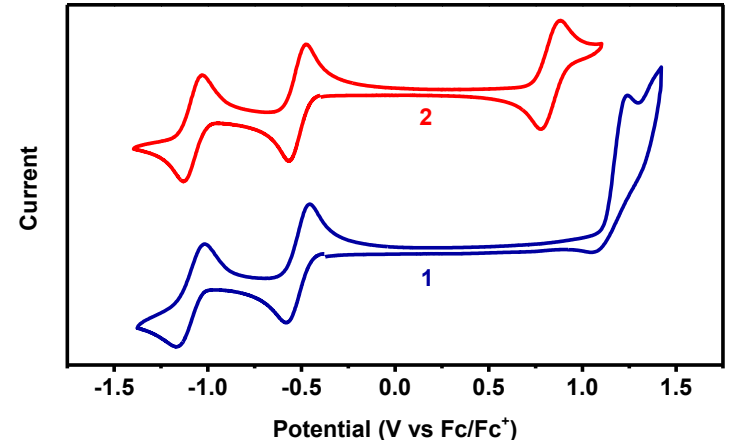

Fig. 4 Cyclic voltammograms of compounds $\mathbf{1}$ (dark blue) and $\mathbf{2}$ (red) in $\mathrm{CH}_{2} \mathrm{Cl}_{2}$ with $\mathrm{nBu}_{4} \mathrm{NPF}_{6}(0.1 \mathrm{M})$ as the supporting electrolyte and saturated calomel electrode as the reference electrode; the potentials are reported relative to $\mathrm{Fc} / \mathrm{Fc}^{+}$.

broad and featureless bands can be assigned to an ICT transition from the polyaromatic donor to the TCBD acceptor moiety, as previously rationalized by theoretical calculations performed with aromatic donors bearing a similar TCBD unit. ${ }^{13}$

In order to evaluate the electronic properties of compounds 1 and 2, we recorded their cyclic voltammograms (Fig. 4). As usual for TCBD derivatives obtained from ynamides, two reversible one-electron reduction waves were observed, the first of which was located at $-0.52 \mathrm{~V}$ vs $\mathrm{Fc} / \mathrm{Fc}^{+}$in both cases, and the second at -1.09 and $-1.08 \mathrm{~V}$ vs Fc/Fc ${ }^{+}$for compounds 1 and $\mathbf{2}$, respectively. These reduction potentials are in line with previously published results. ${ }^{12,13,15}$ More surprisingly, we observed an oxidation wave close to the solvent limit for pyrene derivative $\mathbf{1}$ with an anodic potential peak at $1.24 \mathrm{~V}$ vs $\mathrm{Fc} / \mathrm{Fc}^{+}$. No oxidation wave could be observed with TCBD compounds derived from ynamides in the past, except with very strong donating groups like triphenylamine. ${ }^{12}$ Furthermore, perylene derivative $\mathbf{2}$ showed a reversible oxidation at $0.83 \mathrm{~V}$ vs $\mathrm{Fc} / \mathrm{Fc}^{+}$. The increase in the conjugation of the polyaromatic group thus probably stabilizes the formed radical cation significantly. In conjunction with the unchanged first reduction potential (i.e. similar LUMO energy), the observed lower oxidation potential in $\mathbf{2}$ (associated with an increase in the HOMO energy) is consistent with the bathochromic shift of the ICT band in the UV-vis spectra compared to 1 .

We then investigated the photoluminescence properties of compounds $\mathbf{1}$ and $\mathbf{2}$. In dichloromethane solution no emission was detected, in line with the prior studies indicating a quenching effect of the TCBD fragment. ${ }^{2,6,7}$ However, excitation of the powders of both compounds into the lowest energy absorption band produced an emission that was, remarkably, located in the NIR region. Given the wavelength window in which these compounds emit light, in order to collect the full spectra the PL signals were measured using two different detectors, i.e. a photomultiplier tube (R2658) and an InGaAs photodiode, and normalized so that the two separately acquired parts of each band overlap on $50 \mathrm{~nm}$ (Fig. 5). Pyrene derivative 1 exhibits a large emission band extending from 650 to $1300 \mathrm{~nm}$, with a maximum around $810 \mathrm{~nm}$. Consistently with its increased $\pi$-conjugated system and bathochromicallyshifted absorption spectrum, perylene derivative $\mathbf{2}$ shows a red-shifted emission band between 750 and $1350 \mathrm{~nm}$, with a maximum around $890 \mathrm{~nm}$. The excitation spectra recorded on the powders match the absorption spectra (Fig. S16) and cover the visible range, reaching the first near-infrared window (NIR-

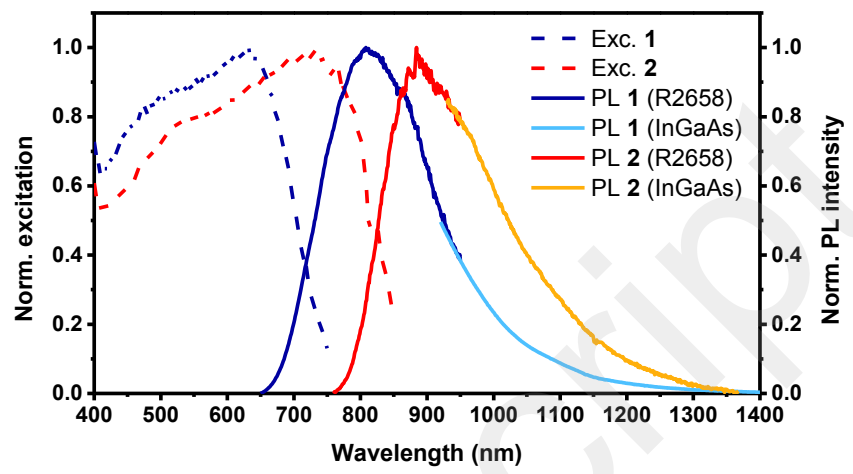

Fig. 5 Normalized excitation spectra (dashed lines) of compounds 1 (detection at $775 \mathrm{~nm}$, dark blue) and $\mathbf{2}$ (detection at $970 \mathrm{~nm}$, red) and normalized PL spectra (solid lines) of compounds 1 ( $\lambda_{\mathrm{exc}}=600 \mathrm{~nm}$, dark blue and light blue) and $2\left(\lambda_{\mathrm{exc}}=700 \mathrm{~nm}\right.$, red and orange) in the solid state (powders) at $293 \mathrm{~K}$.

I, loosely defined between 700 and $950 \mathrm{~nm})^{16}$ with a more substantial response in the case of compound 2 at $750 \mathrm{~nm}$. Compounds $\mathbf{1}$ and $\mathbf{2}$ in the solid state are therefore adapted for both excitation and detection in the NIR-I range. Such a finding suggests that TCBD derivatives present surprising potentialities as NIR emitters, which find various applications such as NIR-OLED ${ }^{17 a}$ or biological imaging, as these wavelengths allow for improved penetration depths compared to visible-wavelength imaging. ${ }^{16}$ Furthermore, while the development of small organic molecules as NIR-I dyes undoubtedly remains a challenging task, ${ }^{17 \mathrm{~b}}$ the design of efficient fluorophores reaching the second near-infrared window (NIR-II, 1000-1700 nm) is an emerging field that may provide considerable advance in deep-tissue imaging. ${ }^{16}$ Interestingly, considering the rather broad signal shape of compounds $\mathbf{1}$ and $\mathbf{2}$ (with a full width at half maximum of $195 \mathrm{~nm}$ in both cases), a significant portion of the PL bands is located in the NIR-II region: this particular PL accounts for $10 \%$ of the emission of $\mathbf{1}$, and $30 \%$ of that of $\mathbf{2}$. The singular photophysical properties of Compounds $\mathbf{1}$ and $\mathbf{2}$ in the solid state imply that these molecules are not only relevant as NIR-I fluorophores but also more strikingly for NIR-I-to-NIR-II fluorescence applications (i.e. excitation is performed in the NIR-I window while emission is detected in the NIR-II window). ${ }^{16 a}$ We ascribe the lack of emission in solution to the previously mentioned intrinsic dynamic processes of TCBD derivatives, which can be minimized in the solid state. To validate this hypothesis, PL measurements were performed in MeTHF glass at 77K and in PMMA film at room temperature. Since the emission of perylene derivative $\mathbf{2}$ was too weak under these conditions to be reliably measured, these experiments were conducted solely using pyrene derivative 1 . A broad emission band could be observed in both media with a blue-shifted maximum around $700 \mathrm{~nm}$ (Fig. S17 and S18). These results confirm the increased emission properties of the 
ICT state in rigid environments, though intermolecular effects cannot be discarded in the powders.

These observations suggest that TCBD compounds might unexpectedly offer a synthetically convenient approach to obtain small organic chromophores with a red-shifted luminescence. To that end, the efficient non-radiative deactivation channels in this type of dyes that accompany torsional motions of the TCBD moiety constitute the main drawback that needs to be addressed to allow for adequate implementation in the various applications, e.g. by using aggregated materials in solution or by designing more sterically encumbered TCBD fragments to enhance their emission properties. Importantly, to support these strategies, the precise nature of the emissive state will need to be investigated to fully assess the influence of intermolecular interactions.

To conclude, we synthesized and characterized two new TCBD derivatives constructed from ynamides bearing a pyrene or a perylene motif. The absorption of compound $\mathbf{1}$ covers most of the visible region, while perylene derivative $\mathbf{2}$ is a panchromatic dye. Additionally, they both emit light in the solid state in the NIR region until $1350 \mathrm{~nm}$ approximately, thus reaching the NIR-II window. This last feature is remarkable for such small organic species, considering their simple design based on a widely used blue fluorescent arene decorated with a single strong electron-accepting moiety. The conceived molecules shed a new light on TCBD compounds as chromophores, opening more perspectives for their use in specific devices requiring NIR emission in the solid state or in biological imaging as suitably designed materials. The results obtained so far prompt us to further explore the intriguing luminescence properties of TCBD derivatives bearing fluorophores, with the aims of uncovering the effect of TCBD acceptor moieties on the photophysical behavior of the chromophores, improving their luminescence in solution, and shifting it farther into the NIR-II range.

\section{Acknowledgements}

This study is part of the project ANR JCJC Fluotet from the Agence Nationale pour la Recherche. Océane Pesset is acknowledged for her contribution to the synthesis of compounds 1 and 2. A. T. B. and C. P. thank the Région Bretagne for funding postdoctoral and doctoral grants, respectively. The authors would like to acknowledge Dr. Olivier Maury and the Laboratoire de Chimie at ENS de Lyon for access to the Horiba Jobin-Yvon fluorometers. Dr. François Riobé's assistance with the corresponding measurements is also greatly appreciated.

\section{Notes and references}

1 a) T. Michinobu, J. C. May, J. H. Lim, C. Boudon, J.-P. Gisselbrecht, P. Seiler, M. Gross, I. Biaggio and F. Diederich, Chem. Commun., 2005, 6, 737-739. b) T. Mochida and S. Yamazaki, J. Chem. Soc. Dalton Trans., 2002, 18, 3559-3564. c) D. Koszelewski, A. Nowak-Król and D. T. Gryko, Chem. - Asian J.,
2012, 7, 1887-1894. d) S. Kato, H. Noguchi, S. Jin and Y. Nakamura, Asian J. Org. Chem., 2016, 5, 246-256. e) T. Shoji, J. Higashi, S. Ito, T. Okujima, M. Yasunami and N. Morita, Chem. Eur. J., 2011, 17, 5116-5129. f) T. Shoji, S. Ito, K. Toyota, M. Yasunami and N. Morita, Chem. - Eur. J., 2008, 14, 8398-8408. g) A. Leliège, P. Blanchard, T. Rousseau and J. Roncali, Org. Lett., 2011, 13, 3098-3101. h) T. Shoji and S. Ito, Chem. - Eur. J., 2017, 23, 16696-16709.

2 M. Sekita, B. Ballesteros, F. Diederich, D. M. Guldi, G. Bottari and T. Torres, Angew. Chem. Int. Ed., 2016, 55, 5560-5564.

3 Y. Patil and R. Misra, J. Mater. Chem. C, 2019, 7, 13020-13031.

4 a) X. Wu, J. Wu, Y. Liu and A. K.-Y. Jen, J. Am. Chem. Soc., 1999, 121, 472-473. b) C. Cai, I. Liakatas, M.-S. Wong, M. Bösch, C. Bosshard, P. Günter, S. Concilio, N. Tirelli and U. W. Suter, Org. Lett., 1999, 1, 1847-1849.

5 T. Michinobu and F. Diederich, Angew. Chem. Int. Ed., 2018, 57, 3552-3577.

6 F. Monti, A. Venturini, A. Nenov, F. Tancini, A. D. Finke, F. Diederich and N. Armaroli, J. Phys. Chem. A, 2015, 119, 1067710683.

7 a) F. Tancini, F. Monti, K. Howes, A. Belbakra, A. Listorti, W. B. Schweizer, P. Reutenauer, J.-L. Alonso-Gómez, C. Chiorboli, L. M. Urner, J.-P. Gisselbrecht, C. Boudon, N. Armaroli and F. Diederich, Chem. - Eur. J., 2014, 20, 202-216. b) K. A. Winterfeld, G. Lavarda, J. Guilleme, D. M. Guldi, T. Torres and G. Bottari, Chem. Sci., 2019, 10, 10997-11005.

8 a) T. Michinobu, C. Boudon, J.-P. Gisselbrecht, P. Seiler, B. Frank, N. N. P. Moonen, M. Gross and F. Diederich, Chem. - Eur. J., 2006, 12, 1889-1905. b) Z. Pokladek, N. Ripoche, M. Betou, Y. Trolez, O. Mongin, J. Olesiak-Banska, K. Matczyszyn, M. Samoc, M. G. Humphrey, M. Blanchard-Desce and F. Paul, Chem. - Eur. J., 2016, 22, 10155-10167.

9 J. Xu, X. Liu, J. Lv, M. Zhu, C. Huang, W. Zhou, X. Yin, H. Liu, Y. Li and J. Ye, Langmuir, 2008, 24, 4231-4237.

10 a) K. A. Winterfeld, G. Lavarda, J. Guilleme, M. Sekita, D. M. Guldi, T. Torres and G. Bottari, J. Am. Chem. Soc., 2017, 139, 5520-5529. b) A. H. Dar, V. Gowri, A. Gopal, A. Muthukrishnan, A. Bajaj, S. Sartaliya, A. Selim, Md. E. Ali and G. Jayamurugan, J. Org. Chem., 2019, 84, 8941-8947.

11 a) G. Evano, A. Coste and K. Jouvin, Angew. Chem. Int. Ed., 2010, 49, 2840-2859. b) K. A. DeKorver, H. Li, A. G. Lohse, R. Hayashi, Z. Lu, Y. Zhang and R. P. Hsung, Chem. Rev., 2010, 110, 50645106.

12 M. Betou, N. Kerisit, E. Meledje, Y. R. Leroux, C. Katan, J.-F. Halet, J.-C. Guillemin and Y. Trolez, Chem. - Eur. J., 2014, 20, 9553-9557.

13 M. Betou, R. J. Durand, D. A. Sallustrau, C. Gousset, E. Le Coz, Y. R. Leroux, D. L. Toupet, E. Trzop, T. Roisnel and Y. Trolez, Chem. Asian J., 2017, 12, 1338-1346.

14 a) A. Coste, G. Karthikeyan, F. Couty and G. Evano, Angew. Chem. Int. Ed., 2009, 48, 4381-4385. b) Y. Yang, S. Ji, F. Zhou and J. Zhao, Biosens. Bioelectron., 2009, 24, 3442-3447.

15 R. Bouvier, R. Durand, L. Favereau, M. Srebro-Hooper, V. Dorcet, T. Roisnel, N. Vanthuyne, Y. Vesga, J. Donnelly, F. Hernandez, J. Autschbach, Y. Trolez and J. Crassous, Chem. - Eur. J., 2018, 24, 14484-14494.

16 a) J. Zhao, D. Zhong and S. Zhou, J. Mater. Chem. B, 2018, 6, 349-365. b) F. Ding, Y. Zhan, X. Lu and Y. Sun, Chem. Sci., 2018, 9, 4370-4380.

17 a) A. Zampetti, A. Minotto and F. Cacialli, Adv. Funct. Mater., 2019, 29, 1807623. b) Z. Guo, S. Park, J. Yoon and I. Shin, Chem. Soc. Rev., 2013, 43, 16-29. 